\title{
Avaliação docente antidemocrática: influência na prática pedagógica
}

\author{
Raimundo Nonato de Souza Bouth*
}

Resumo

A pesquisa desenvolveu-se em um centro de ensino particular onde a prática pedagógica docente é avaliada por alunos e seus resultados dão fulcro à tomada de decisões do proprietário/gestor escolar. $\mathrm{O}$ artigo tem como propósito identificar se a aplicação da avaliação docente, enquanto instrumento de gestão antidemocrática, altera a prática pedagógica docente, influenciando no processo de ensino-aprendizagem. A metodologia aplicada é qualitativa, embasada em análise fenomenológica, descritiva e bibliográfica, com técnicas de questionário, entrevista despadronizada e observação sistemática para constatar-se ou não a solidez das respostas. Os resultados demonstram que a avaliação docente proporciona, por parte do gestor, docentes e alunos, ações restritivas pedagógicas, retaliadoras hierárquicas, controladoras patronais e punitivas de vinditas, coexistindo, assim, aversão à avaliação por parte dos professores. A avaliação docente não pode restringir a prática pedagógica docente, mas deve se constituir em momento de expectativa pelos sujeitos da instituição para que, com seus resultados, busque-se a melhoria do processo de ensino-aprendizagem.

Palavras-chave: Avaliação docente. Gestão escolar antidemocrática. Prática pedagógica.

\section{Introdução}

$\mathrm{Na}$ evolução histórica da educação, os projetos de avaliação educacional passaram a constituir-se como ferramenta fundamental de gestão democrática educacional necessária às instituições de ensino, sejam elas públicas ou privadas. Os diversos modelos de avaliação educacional procuram estabelecer um grau de qualidade às instituições de ensino, que devem sempre buscar e apresentar condição favorável à formação educacional, capaz de proporcionar e coadunar a todos aqueles que formam a comunidade da instituição a concepção de uma consciência reflexiva e crítica.

\footnotetext{
Recebido: 20/03/2013 - Aprovado: 09/07/2013
}

http://dx.doi.org/10.5335/rep.2013.3562

Mestre em Ciências da Educação e Doutorando em Ciências da Educação pela Universidad Autónoma de Asunción (UAA). E-mail: nonatobouth@hotmail.com. 
A avaliação educacional deve proporcionar informações sobre a qualidade de um programa educativo ou de um centro educacional em toda sua amplitude. Isso é possível por meio de um estudo ordenado e sistêmico fundamentado em evidências. Contudo, se esse instrumento for utilizado de forma inadequada, em gestão escolar antidemocrática, as consequências para o processo de ensino-aprendizagem podem ser evidentes.

Dentro do contexto das avaliações educacionais, a avaliação do corpo docente, em geral realizada pelo universo de alunos da escola e/ou por um grupo de representantes da instituição educacional, pode ser entendido como um instrumento observador, fiscalizador e controlador da prática pedagógica. Para compreender-se essa relação entre a avaliação docente e o caráter controlador e fiscalizador da prática pedagógica dos avaliados, além das evidências in loco, recorre-se aos estudos de autores renomados sobre o assunto: Bloom, Hastings e Madaus (1983), Haydt (1992), Freire (1991, 1996), Ramos e Moraes (2000), Sobrinho (2003), Luckesi (1984, 2005), Afonso (2005), Silva e Menezes (2005), Souza (2005), Perrenoud (2007), Demo (2007, 2008), Castanheira e Ceroni (2008), Romão (2008), Leite e Kager (2009) e Antunes (2010).

Para melhor compreensão deste trabalho, levanta-se o seguinte problema: a prática pedagógica dos professores é influenciada por uma avaliação docente antidemocrática? Diante dessa questão, o artigo tem como propósito identificar se a aplicação da avaliação docente, enquanto instrumento de gestão antidemocrática, altera a prática pedagógica do corpo de professores do centro de estudos em questão, influenciando no processo de ensino-aprendizagem.

A pesquisa apresenta metodologia qualitativa embasada em análise fenomenológica (de onde as situações foram descritas tal como se apresentaram ao pesquisador), descritiva e bibliográfica, com uso das técnicas do questionário fechado, de múltiplas escolhas, entrevista despadronizada e observação sistemática, com 0 propósito de constatar ou não a solidez das respostas apontadas nos questionários e entrevistas.

A coleta de dados foi dividida em duas etapas, para facilitar o entendimento e a organização das informações. Cada uma das etapas foi desenvolvida com dinâmicas diferentes e disposta da seguinte forma: $1^{\underline{a}}$ etapa - realizou-se a aplicação dos questionários aos alunos, coordenadores e docentes, concomitantemente a entrevistas com parte do corpo docente, proporcionando condições de analisar suas opiniões diante do estudo em apreço; $2^{\mathrm{a}}$ etapa - ocorreu a observação sistemática, a fim de verificar-se a autenticidade do que foi dito e respondido por alunos e docentes. 
Como se constata na $1^{\underline{a}}$ etapa da pesquisa, a instituição, ao aplicar a avaliação docente, considera alunos, coordenadores e os próprios docentes os atores responsáveis por responder aos questionários que embasam as evidências da avaliação. Porém, como esses atores procedem, considerando suas reais condições psicoeducacionais e pedagógicas, para constituírem esse tipo de avaliação perante uma gestão educacional antidemocrática? No caso específico dos docentes, eles promovem alterações negativas em suas práticas pedagógicas como forma de melhor serem avaliados pelos atores avaliadores?

Deve-se aludir a essa denominação de "prática pedagógica docente" como significado do relacionamento entre professor e alunos, esclarecimento de dúvidas, manutenção da ordem e da disciplina em sala de aula, modelo e nível de prova bimestral aplicada aos alunos, utilização de material didático compatível à série, assiduidade e pontualidade.

A pesquisa justifica-se pela importância que o processo avaliativo representa para que a gestão escolar fundamente-se na busca pela melhoria da qualidade do processo de ensino-aprendizagem, gerando uma evolução interna qualitativa das instituições educacionais públicas ou, como no caso em questão, das instituições educacionais privadas.

\section{Avaliação docente no contexto do processo educacional: para que avaliar docentes? A quem interessa essa avaliação?}

A educação, por ser ato antrópico, é falha, e um de seus agentes é o docente, mesmo que esse se considere um educador, pois ainda existem alguns que não evoluíram em seus conceitos e em suas ideias e, por isso, ainda se veem como o centro do processo de ensino-aprendizagem, quando não de todo o processo educacional.

Em primeira instância, identifica-se que esse processo é interativo, e, não havendo a interação professor-aluno, o ato de educar torna-se inconcluso. Somente a partir do processo interativo aluno-professor é que este último será considerado elemento gerador de alunos produtivos e renovador de ideias e concepções. A interatividade professor-aluno pode ser caracterizada por diferentes elementos, dentre os quais, a avaliação aplicada aos docentes.

A avaliação educacional busca estabelecer um grau de qualidade em diferentes dimensões e segmentos, como espaço físico da instituição, seus serviços técnico-administrativos, prática pedagógica dos docentes, comportamento e evolução educacional dos alunos e até recursos tecnológicos utilizados como ferramenta de propulsão do ensino e da aprendizagem. 
As políticas públicas influenciam diretamente na política educacional, em especial aquelas ligadas a organismos internacionais, como o Fundo Monetário Internacional (FMI) e o Banco Mundial. Todavia, o docente não pode continuamente alegar que os desleixos ocorridos na educação decorrem do sistema, para que suas afirmações não se esvaiam ou passem a ser consideradas como ato de defesa para acobertar ou justificar sua falta de compromisso com a instituição-escola ou sua carência de formação didático-pedagógica.

Assevera-se que o sistema pouco eficaz provoca carência de financiamentos na educação, promove uma educação de reprodução, e não de renovação, cria barreira para o aprendizado dos alunos, comprime e enfraquece ações docentes e promove uma escola considerando seu nível social. E assim, a escola e os docentes são incluídos como meros componentes no mundo do capital, do mercado.

No entanto, não é o sistema que ministra as aulas, mas sim o professor, e ele não pode, simplesmente, ministrar aula ruim por ser pessimamente pago pelo sistema. É, sim, a péssima formação desse docente que o conduz a essas falhas. Para o Instituto Nacional de Estudos e Pesquisas Educacionais (INEP), grande parcela do alunado não consegue aprender em decorrência dessas falhas. É aí que o sistema frauda certos resultados como forma de escamotear sua ineficiência e ineficácia.

O processo de avaliação à prática pedagógica dos docentes é entendido como ferramenta que contribui para uma reviravolta dessa situação, na busca de melhor qualidade do ensino e da aprendizagem. Então, torna-se necessária, para essa evolução do processo pedagógico, uma avaliação de caráter transformador, ou seja, formativa, voltada à estruturação de uma educação compromissada e empenhada com o social. Isso é imprescindível à formação efetiva de profissionais de qualidade e de cidadãos críticos.

Nesse processo avaliativo, deve-se relacionar o mérito e a atividade pedagógica de qualidade com relevância e efetividade social. Com a eficácia dessa interação, contorna-se a pouca compreensão sobre a avaliação educacional e sua contribuição à produção de conhecimento. A avaliação educacional deve ter eficiência metodológica em prol da eficácia na busca de resultados de qualidade.

Avaliar pressupõe a criação de hierarquias de excelência e, a partir delas, é que serão tomadas decisões de várias ordens, seja para orientar a diversificação de cursos a serem seguidos, seja para certificar antes da entrada no mercado de trabalho e, consequentemente, a contratação, dentre outros (PERRENOUD, 2007). Deve-se ressaltar que avaliar não é medir, nem testar. Haydt (1992) acrescenta que, em sua ótica, não se pode confundir "testar", "medir" e "avaliar". 


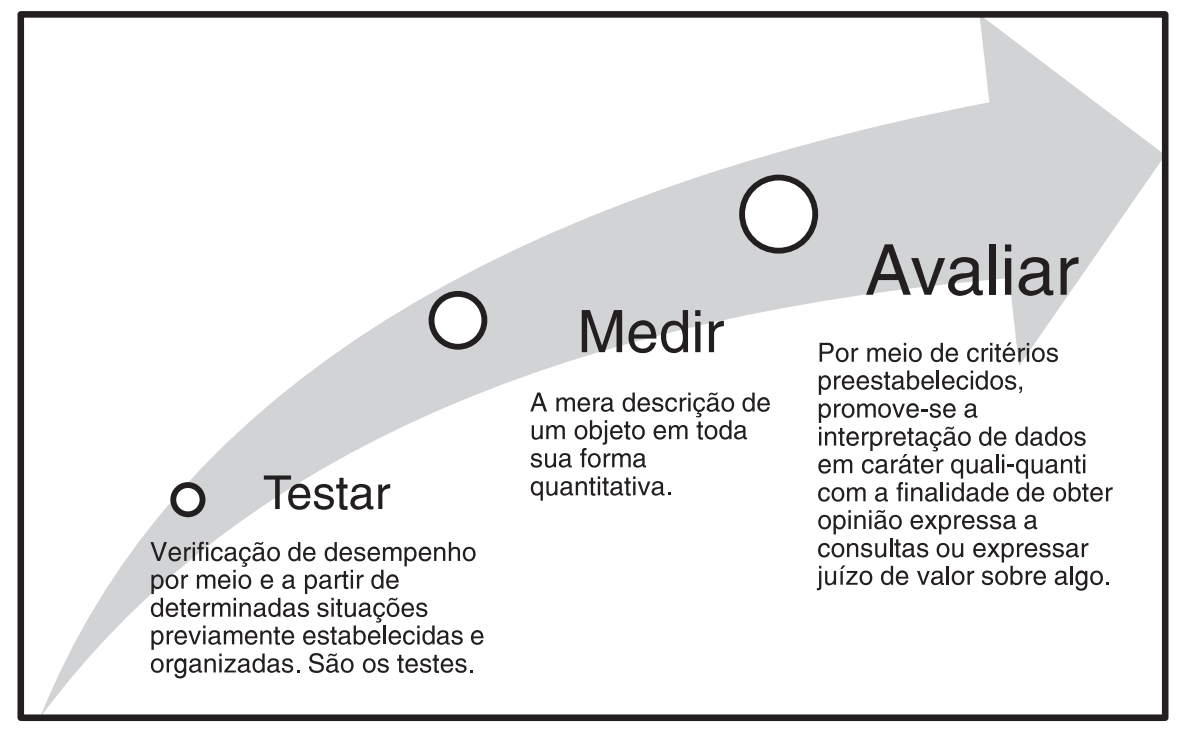

Fonte: adaptado de HAYDT, 1992.

Figura 1 - Testar, medir e avaliar

O processo avaliativo deve ser minucioso e considerar a questão da importância dos critérios para que adquira consistência e confiabilidade.

Quando se questiona sobre o propósito da avaliação, as respostas são diversas, pois vários fatores, internos e/ou externos, devem ser considerados. Por isso, afirma-se, novamente, que adotar uma metodologia é fundamental para a configuração e a validação científica do processo de avaliação.

Assim, segundo os estudos de Silva e Menezes (2005), a metodologia da avaliação deve ser constituída de um processo de observação sistemática para responder aos propósitos preestabelecidos da pesquisa avaliativa. Entende-se, então, que não se deve menosprezar a complexidade de um processo avaliativo, pois toda avaliação reporta-se a ideias, qualidades, escolhas, valores, interesses, grupos, instâncias, poder. Com essa diversidade, a avaliação não poderia esgotar-se em instrumentos simplistas e individuais.

O processo avaliativo na educação sempre teve seu lugar privilegiado como prática pedagógica, mas também é utilizada na regulação, seleção e hierarquização na escola (CASTANHEIRA; CERONI, 2008). Autores como Bloom, Hastings e Madaus (1983) asseveram que a avaliação está relacionada ao controle de qualidade, ou seja, que a avaliação educacional consiste em um meio para aperfeiçoar o processo de ensino-aprendizagem, e, por isso, os procedimentos da avaliação são frequentemente utilizados a fim de se efetuar decisões críticas e, muitas vezes, irreversíveis a respeito de determinadas valorações no sistema educacional. 
Nessa perspectiva, ainda se acrescenta que a avaliação ilumina e instrumentaliza as reformas educacionais, desde a mudança nos currículos, maneiras de organização de cursos e formas gerenciais até novas estruturas do sistema (DIAS SOBRINHO, 2004). Isso quer dizer que o processo de avaliação é instrumento que está no âmago das reformas educacionais e no âmbito de competições institucionais.

No processo avaliativo de docentes, a participação de alunos é crescente e positiva, logo, necessária. Utilizar indicadores adequados e, principalmente, recorrer-se à utilização de uma escala de frequência, ou seja, à constante repetição dos valores atribuídos aos indicadores de qualidade, no lugar de uma escala de valoração única para a atribuição de notas momentâneas, vem se mostrando instrumento mais adequado na busca de um ensino de melhor qualidade. Procura-se, então, exibir ao docente e à instituição de ensino amostragem mais precisa, mas não medição quantitativa de erros, acertos, facilidades e dificuldades do processo de ensino-aprendizagem constituído na escola.

O desempenho do docente pode ser avaliado de formas distintas, mas complementares. Por um lado, pode-se avaliar os aspectos técnico e científico, ou seja, o domínio do conteúdo de sua área específica, e, por outro, o desempenho didático-pedagógico, o qual se refere ao domínio das técnicas do ensino-aprendizagem.

O desempenho técnico-científico pode ser avaliado segundo critérios como a clareza e a objetividade na apresentação e no desenvolvimento do conteúdo ministrado e das atividades escolares, explicitação da fundamentação teórica do conteúdo e das atividades e explicitação da relevância e da utilidade do conteúdo trabalhado. Por sua vez, o desempenho didático-pedagógico pode ser avaliado por indicadores como explicitação do conteúdo de forma integrada e complementar com o conteúdo de outras disciplinas, uso do material didático, aplicação de atividades práticas e estruturadas, procedimentos pedagógicos, espontaneidade e ausência de pressão para com os alunos, estímulo ao questionamento, pontualidade e assiduidade.

A avaliação docente propõe-se, em primeira instância, a contribuir no aperfeiçoamento, de forma gradativa, do processo de ensino-aprendizagem. No entanto, existem vários modelos avaliativos que nem sempre condizem com os objetivos para os quais essa avaliação foi proposta. Para ser coerente e eficaz na busca de seus objetivos, esta deve recorrer a diversificados instrumentos de coleta de dados, mas é fundamental atentar para a sua metodologia de aplicabilidade, a fim de que não ocorram distorções em sua finalidade, como o atendimento a certos interesses particulares e o descaso pelos resultados obtidos por parte dos docentes.

É buscando otimizar o trabalho docente que a prática avaliativa torna-se imprescindível. É importante que cada instituição de ensino implante seu próprio 
processo avaliativo de docentes, mas que atendam seus interesses relacionados à evolução do processo educacional, e não do capital. Tal avaliação deve considerar, portanto, as características da instituição, de seus alunos e dos próprios professores.

\section{Avaliação docente e gestão antidemocrática}

A educação como instrumento democrático foi lançada nos anos 1920 por Anísio Teixeira, Fernando de Azevedo, Lourenço Filho, Almeida Júnior, Roquete Pinto e Pascoal Leme, que inspiraram o movimento dos Pioneiros da Educação Nova.

$\mathrm{O}$ crescente protagonismo da avaliação não pode ser compreendido à margem da natureza das políticas públicas e educacionais contemporâneas, nem, mais especificamente, à margem do papel e da redefinição do Estado em contexto de globalização. Porém, a avaliação educacional, algumas vezes, pode servir de instrumento para uma gestão que não se insira em contexto democrático.

Inicialmente impulsionada pela emergência de governos neoconservadores e neoliberais, há duas décadas e meia, a avaliação tornou-se obsessiva e unidirecional, quer pelo fato de manter a sua presença de forma relativamente indiferente à natureza de governos de outras orientações político-partidárias, quer pelo fato de continuar a contribuir para maximizar as funções de controle e de legitimação, em vez de apoiar mecanismos democráticos de prestação de contas e de responsabilização (accountability) mais congruentes com a promoção de justiça social e educacional (AFONSO, 2005).

A democracia, direta ou indireta, expressa a vontade do povo, e, assim, a gestão na escola, seja pública ou privada, em suas relações com a comunidade, deve seguir uma linha horizontal de ações. Contudo, o que se observa, em alguns casos, como o abordado por esse artigo, é uma gestão com ações verticais e que não atendem aos preceitos democráticos.

A gestão autoritária, centralizadora e não transparente é causadora de alienação profissional e educacional levando o docente a promover práticas pedagógicas inadequadas que refletem deficiências no processo de ensino-aprendizagem. Não se pode aceitar, em um país democrático como o Brasil, cujo estágio é resultante de muitos protestos e lutas, uma gestão escolar embasada em cargos hierárquicos, mesmo em escolas de cunho particular, pois a instituição, enquanto escola, foi legalizada e instituída para ensinar, formar e educar por meio de ensino-aprendizagem de qualidade. É imperiosa uma gestão democrática em qualquer nível de escolaridade, seja a escola pública ou privada. 
A metodologia do processo avaliativo docente em escolas particulares, quando aplicada de forma equivocada, em decorrência de uma gestão escolar antidemocrática, pode gerar nos professores reflexos em suas práticas pedagógicas contrários a determinados paradigmas educacionais. Assim, compreende-se que o comportamento docente é moldado mediante a estimulação externa; portanto, o indivíduo não participa das decisões curriculares tomadas por um grupo do qual ele não faz parte (MIZUKAMI, 1986, p. 28). Isso quer dizer que, se o corpo docente é excluído do planejamento da avaliação de si mesmo, parte dele terá entendimento equivocado de seu processo avaliativo e não aceitará plenamente seus resultados.

A avaliação da prática pedagógica de professores em escolas particulares, mesmo considerando que essas instituições estão inseridas no contexto do mercado capitalista, não pode ser revestida de caráter restritivo pedagógico, retaliador hierárquico, controlador administrativo patronal, punitivo de vindita e punitivo de capital. Entende-se que essas características avaliativas refletem na gestão escolar antidemocrática.

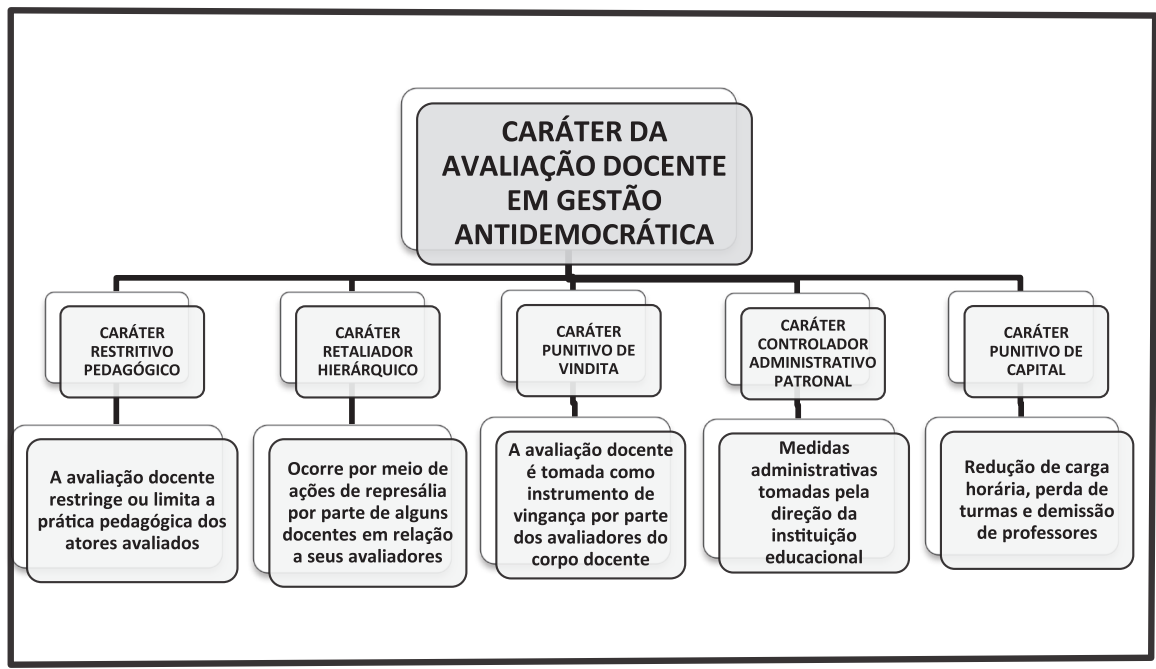

Fonte: Nonato Bouth - a pesquisa.

Figura 2 - Equívocos do processo avaliativo

O caráter restritivo pedagógico ocorre quando os resultados da avaliação docente restringem ou limitam as práticas pedagógicas dos atores avaliados que seriam favoráveis ao processo de ensino-aprendizagem, mas que não são consideradas eficazes e condizentes com certos interesses particulares de alunos, da direção e de coordenadores. $\mathrm{O}$ caráter restritivo pedagógico da avaliação docente pode ser confirmado na pesquisa de Freitas (2003), asseverando que a lógica desse modelo 
não é independente da lógica da escola; ao contrário, ela é produto de uma escola que se separou da vida e das práticas sociais. Como consequência, o autoritarismo é o elemento necessário para a garantia desse modelo social, daí a prática da avaliação manifestar-se autoritária. Essa concepção da avaliação docente implica, pois, prática pedagógica que, por sua vez, está a serviço de um modelo dominante identificado como liberal conservador.

Nas pesquisas de Luckesi (1984), afirma-se que esse modelo avaliativo contempla três pedagogias distintas: a pedagogia tradicional, a pedagogia renovada ou escolanovista e a pedagogia tecnicista. Esse grupo de "pedagogias" está preocupado com a reprodução e a conservação da sociedade, propondo práticas autoritárias de avaliação em qualquer nível.

O caráter retaliador hierárquico ocorre por meio de ações de represália por parte de alguns docentes que receberam de seus avaliadores, os alunos, alguma restrição qualitativa e/ou quantitativa. Considerando-se paradigmas educacionais hierárquicos, na escola, em geral, os alunos estão, "supostamente", em posição inferior à dos docentes. No entanto, algumas vezes, esse paradigma hierárquico sofre mudanças abruptas, pois, em instituições de ensino particular, o aluno passa a ser considerado cliente-consumidor, e, por isso, seus interesses devem ser atendidos de forma que não se comprometa a circulação de capital.

Ressalta-se a pesquisa de Santo e Santos (2010), os quais relatam que tais avaliações ocasionam mal-estar docente, pois os professores sentem-se encurralados pelos alunos, visto que os consideram ineptos para uma avaliação dessa magnitude. As rodas informais de discussões com professores demonstram claramente a insatisfação do grupo diante de processo avaliativo de desempenho em que o avaliador é unicamente o sujeito do processo de ensino-aprendizagem.

O caráter retaliador hierárquico pode ser expresso pelas palavras de Freitas (2003), que, em suas pesquisas, infere que a parte mais dramática e relevante da avaliação docente localiza-se nos subterrâneos onde os juízos de valor ocorrem. Impenetráveis, eles regulam a relação professor-aluno e vice-versa, e esse jogo de representações vai construindo imagens e autoimagens que terminam interagindo com as decisões metodológicas do professor. Os professores, se não forem capacitados para tal, tendem a tratar os alunos conforme os juízos que vão fazendo a seu respeito, quando começa a ser jogado o destino desses discentes, para o sucesso ou para o fracasso.

Com base nas pesquisas de Leite e Kager (2009, p. 126-127), entende-se que essa potencialização da aversão pelo professor ocorre por meio de diferentes formas de agir. $\mathrm{Na}$ maior parte das vezes, o mau relacionamento entre professor e alunos gera sentimentos de raiva, ódio e a sensação de desprezo e humilhação por parte 
desses últimos. Um instrumento retaliador hierárquico por parte do docente perante o aluno ou a classe que o avaliou - segundo a concepção do próprio docente - de modo inadequado pode ser o modelo das avaliações bimestrais.

$\mathrm{Na}$ contramão do processo retaliador hierárquico e acompanhado dos sentimentos dos alunos, há o caráter punitivo de vindita. Esse ocorre quando o alunado usa da avaliação como instrumento de vingança por opor-se às práticas pedagógicas de alguns professores.

Agindo de acordo com o caráter punitivo de capital, a direção patronal reduz a carga horária, retira turma, podendo chegar a demitir professores caso sua quantificação mostre-se baixa quando aplicada a avaliação pelos alunos. O caráter punitivo de capital pode ser compreendido pelos estudos de Chiavenato (2000), Costa (2007), Santo e Santos (2010).

Costa (2007) assevera que a avaliação docente está contida no discurso pedagógico adotado pela instituição. Diante disso, resta saber qual é o posicionamento da instituição que resolve utilizar essa avaliação e quais são as reais finalidades de sua prática. No estudo de Chiavenato (2000), porém, consta que a avaliação de desempenho docente transcende o olhar centrado apenas no colaborador, visto que também fornece subsídios imprescindíveis para a gestão da organização. É consenso que um processo de avaliação de desempenho sistematizado é capaz de localizar problemas relacionados à liderança, à integração entre pessoas e/ou organização, servindo até mesmo para avaliar o hiper, sub ou desaproveitamento de pessoas nas suas respectivas funções. Chiavenato (2000) afirma, ainda, que os resultados de um processo de avaliação de desempenho podem colaborar com a instituição na formulação de políticas direcionadas à gestão de pessoas, adequadas às necessidades da empresa e dos seus colaboradores. Assim, os interesses dos alunos e do capital devem ser preservados, sobretudo.

Santo e Santos, fundamentados na pesquisa de Lucena (2009), acrescentam que a avaliação docente reflete que as organizações estão empenhadas em tornar o desempenho humano mais "eficaz na obtenção de resultados", com vistas ao "aumento da produtividade, objetivando o retorno rentável e a participação no sucesso do negócio" (2010, p. 3).

O Quadro 1, na sequência, apresenta, de forma concisa, as principais vantagens e desvantagens observadas no processo de avaliação de desempenho do docente. Embora a avaliação de desempenho seja capaz de fornecer importantes subsídios à retroalimentação da práxis educativa, torna-se necessário monitorá-la, para que não resulte na instauração de processo de vingança do professor contra 0 aluno (e vice-versa), tampouco em fonte de desmotivação e mal-estar docente. Esse quadro integra estudos de Martins (2008) e proporciona melhor compreensão sobre o caráter punitivo de vindita e caráter punitivo de capital. 


\begin{tabular}{|l|l|}
\hline \multicolumn{1}{|c|}{$\begin{array}{c}\text { VANTAGENS DA AVALIAÇÃO DE } \\
\text { DESEMPENHO DOCENTE }\end{array}$} & \multicolumn{1}{|c|}{$\begin{array}{c}\text { DESVANTAGENS DA AVALIAÇÃO DE } \\
\text { DESEMPENHO DOCENTE }\end{array}$} \\
\hline $\begin{array}{l}\text { O professor pode refletir sobre as informações } \\
\text { apresentadas na avaliação de desempenho. } \\
\text { O docente pode sentir-se motivado a partir de } \\
\text { políticas de remuneração resultantes de seu } \\
\text { desempenho. } \\
\begin{array}{l}\text { Favorece a formação continuada do docente, } \\
\text { por meio do rompimento de sua "inércia" } \\
\text { pessoal. }\end{array}\end{array}$ & $\begin{array}{l}\text { O aluno pode "vingar-se" do professor na } \\
\text { avaliação. } \\
\text { O docente pode sentir-se desmotivado a partir } \\
\text { de políticas de remuneração resultantes de seu } \\
\text { desempenho. } \\
\text { visão dos alunos. }\end{array}$ \\
\hline
\end{tabular}

Fonte: MARTINS, 2008.

Quadro 1 - Vantagens x desvantagens da avaliação de desempenho docente

De acordo com Venturini et al. (2008), a satisfação dos alunos está diretamente relacionada ao seu próprio interesse e ao envolvimento do professor. Assim, eles são influenciados pela organização do curso e pela interação professor-estudante (VENTURINI et al., 2008 apud MARTINS, 2008, p. 4).

O caráter controlador administrativo patronal corresponde às medidas administrativas tomadas pela direção da instituição educacional. Isso ocorre quando certas práticas pedagógicas de alguns professores contradizem os interesses dos proprietários da instituição, levando a que se entenda, novamente, que os alunos são, acima de tudo, clientes-consumidores.

Nesse contexto do caráter administrativo patronal, os estudos de Luckesi (1984) evidenciam que a avaliação é um julgamento de valor sobre manifestações relevantes da realidade, tendo em vista uma tomada de decisão; ou seja, avaliar implica a emissão de julgamentos de valores, a partir de dados coletados, visando a uma tomada de decisão. Na prática escolar, qualquer desses elementos pode ser perpassado por concepções autoritárias. Porém, o componente da avaliação mais sensível à questão do poder é a tomada de decisão (LUCKESI, 1984, p. 9).

Nas escolas de cunho particular, a gestão democrática ainda parece distante. O gestor, normalmente o proprietário da escola, não vê com bons olhos a participação da comunidade escolar nas decisões de impacto da escola. $\mathrm{O}$ gestor/proprietário considera-se dono da razão e das certezas. Parece que somente ele sabe o que é melhor para sua escola, os caminhos para se atingir as metas, decididas individualmente pelo poder gestor, mas o objetivo maior da escola, que é a educação de qualidade a partir de eficiente processo de ensino-aprendizagem, jamais será alcançado. Sua gestão está voltada para seus interesses particulares, mas não para a qualidade e a evolução desse processo. Sua gestão organizacional centralizadora 
leva-o a ter certeza de que não necessita prestar contas da evolução do processo educacional aos demais atores que constituem a escola.

Assim, o gestor/proprietário revela à comunidade escolar quem tem a autoridade e o poder de decidir. Como forma de escamotear esse modelo de gestão centralizadora, a participação de outros atores nas decisões da escola é tímida e, sobretudo, controlada, o que leva a comunidade escolar à inércia, à falta de iniciativa. Tudo deve ser iniciado, indicado e, acima de tudo, ordenado pelo gestor. Esse comportamento é resultante do receio de ações gestoras com caráter restritivo pedagógico, retaliador hierárquico, controlador patronal e punitivo de vindita.

A avaliação docente passa a ser o instrumento desse controle, ainda mais quando sua metodologia tem essa função, embora aparentemente não pareça, na medida em que esta aflora com certa perspicácia. Daí vão coexistir aversão à metodologia avaliativa por parte dos docentes e consequentes alterações comportamentais pedagógicas comprometedoras ao ensino-aprendizagem.

Os processos avaliativos merecem toda atenção, principalmente para as implicações políticas da avaliação, suas relações com o planejamento e a prática de ensino e, finalmente, seus aspectos psicológicos do ponto de vista político-pedagógico, pois é uma tradição antidemocrática e autoritária, centrada na pessoa do professor e no sistema de ensino, e não em quem aprende (LUCKESI, 2005). A avaliação docente, quando utilizada em seus resultados de forma equivocada, reflete negativamente na prática pedagógica docente, prejudicando o processo de ensino-aprendizagem como um todo.

Ao mesmo tempo, Dias Sobrinho (2004) assevera que, se a avaliação fosse isenta de valores, fosse mero instrumento técnico, não produziria contradições e, portanto, não se transformaria em campo de disputas acirradas - o que, aliás, ocorre com qualquer ação ou fato social.

A liberdade sem limite é tão negada quanto a liberdade asfixiada ou castrada (FREIRE, 1996). Em algumas instituições de ensino, a avaliação do docente serve apenas para o controle da prática pedagógica por parte dos diretores-proprietários e, muitas vezes, em outras instituições, acaba gerando reflexos socioeconômicos irreversíveis no contexto profissional do professor. Isso porque, em alguns casos, os docentes perdem carga horária ou, então, chegam a submeter-se à demissão, quando os resultados avaliativos opõem-se aos reais interesses daqueles que controlam esse processo. Assim, a avaliação desempenha não só papel importante na relação pedagógica, como também intervém no controle que as instituições escolares exercem sobre o trabalho dos professores (AFONSO, 2005).

Percebe-se que a avaliação, quando foge de sua essência educativa, gera controvérsias e rejeições ao processo, tornando sua aplicabilidade cada vez mais difícil. 
São raras as vezes em que se percebe a incoerência agressiva existente entre as afirmações progressivas e o estilo desastrosamente elitista de ser intelectual. E que dizer do educador que se diz progressista, mas na prática pedagógica é eminentemente autoritário? (FREIRE, 1996).

Nesse contexto, entende-se que a avaliação não é intuitivamente óbvia. É preciso o desenvolvimento de uma cultura da avaliação para que se possa produzir todas as consequências benéficas ao ensino (SOUZA, 2005). Além disso, as palavras de Romão (2008) asseveram que a impossibilidade da avaliação correta é atribuída à complexidade da atividade humana que deve ser avaliada.

Em decorrência do processo avaliativo, não se pode aceitar docentes com certas ações comportamentais pedagógicas que indiquem intenção de burlar a inteligência de seus alunos. A avaliação docente levará a conflitos quando for vista como instrumento para determinar quais são os melhores e piores ou para definir quem são os responsáveis pelas insuficiências e/ou dificuldades do sistema educativo.

No entanto, reluzentes as afirmações de Antunes (2010), quando menciona que o professor bonzinho, camarada, permissivo, manobrável é professor alienado, que vê, inerte, extinguirem-se sua vontade e sua paixão, bem como sua capacidade de decidir sobre o que produz, perdendo sua identidade como pessoa e a dignidade como integrante de uma classe profissional. Deve-se ressaltar que a conceituação de alienação é tratada como processo no qual há a perda de identidade, individual ou coletiva; falta de autonomia, dependência.

O docente crítico é, também, um educador, o qual dialoga com os alunos, sendo o diálogo visto como uma forma de aprendizagem e um modo de levar esses atores a assumir posturas cognoscentes, ou seja, de seres que conhecem (FREIRE, 1996). Ocorre, porém, que alguns docentes resistem em aceitar a crítica, embora sejam profissionais do questionamento.

Pode-se considerar que esses professores rejeitam, ao mesmo tempo, a ideia de serem avaliados, mas não podem agir dessa maneira, na medida em que essa atitude encobre uma grande contradição. Afinal, o avaliador não pode se negar a ser avaliado, para não perder a autoridade de avaliar, impedindo que seja feito consigo o que faz com os outros (DEMO, 2007). É corrente, sobretudo em entidades privadas, avaliar o professor pelo aluno, que, em certa medida, detém a palavra final, especialmente quando entra em cena o discurso neoliberal do cliente (DEMO, 2008).

"A relação professor-aluno, enquanto relação avaliador-avaliado, é vivida como relação de poder na medida em que a avaliação é compulsória [...] e impõe unilateralmente uma grelha de interpretação da realidade permitindo que a relação entre avaliador e avaliado seja vivida como relação de dominação" (AFONSO, 2005, 
p. 20). Contudo, quando ocorre o inverso, ou seja, o professor passa a ser avaliado, não se aceita uma postura dominadora por parte dos alunos, pois os docentes alegam que estes não apresentam condições de conhecimento para medir o seu saber.

Por isso, tanto para a escola como para o docente, é importante que se convoque um grupo externo para promover a avaliação de ambos, pois, nesse caso, a externalidade do avaliador comprometerá minimamente o resultado do processo avaliativo, no qual o comportamento pedagógico do docente deverá ser preciso, correto e ético.

\section{Resultados}

Os resultados foram embasados na aplicação de questionário fechado a cem alunos do terceiro ano do ensino médio, todos respondidos e entregues; oito coordenadores e 24 docentes. Aplicaram-se, também, as técnicas da entrevista e da observação sistemática.

A análise dos gráficos, resultantes das respostas contidas nos questionários, mostra-nos opiniões divergentes e controversas quando comparadas as respostas dos alunos e coordenadores às dos docentes. As controvérsias são percebidas pela entrevista e pela observação sistemática - anotadas tecnicamente - da ação cotidiana escolar dos atores em foco, cotejadas com as informações por eles prestadas nos questionários da pesquisa.

Dentre as respostas dadas às questões contidas nesse instrumento, três, a seguir identificadas (Gráfico 1), chamam atenção por levarem a muitas contradições em relação à postura cotidiana dos alunos, coordenadores e docentes.

Q1 - Ocorrem equívocos metodológicos na aplicação da avaliação docente, gerando alterações na prática pedagógica dos docentes?

Q2 - Os alunos utilizam-se da avaliação docente como forma de promover retaliações a ações de determinado professor?

Q3 - Os resultados da avaliação docente apresentam credibilidade perante a comunidade escolar? 


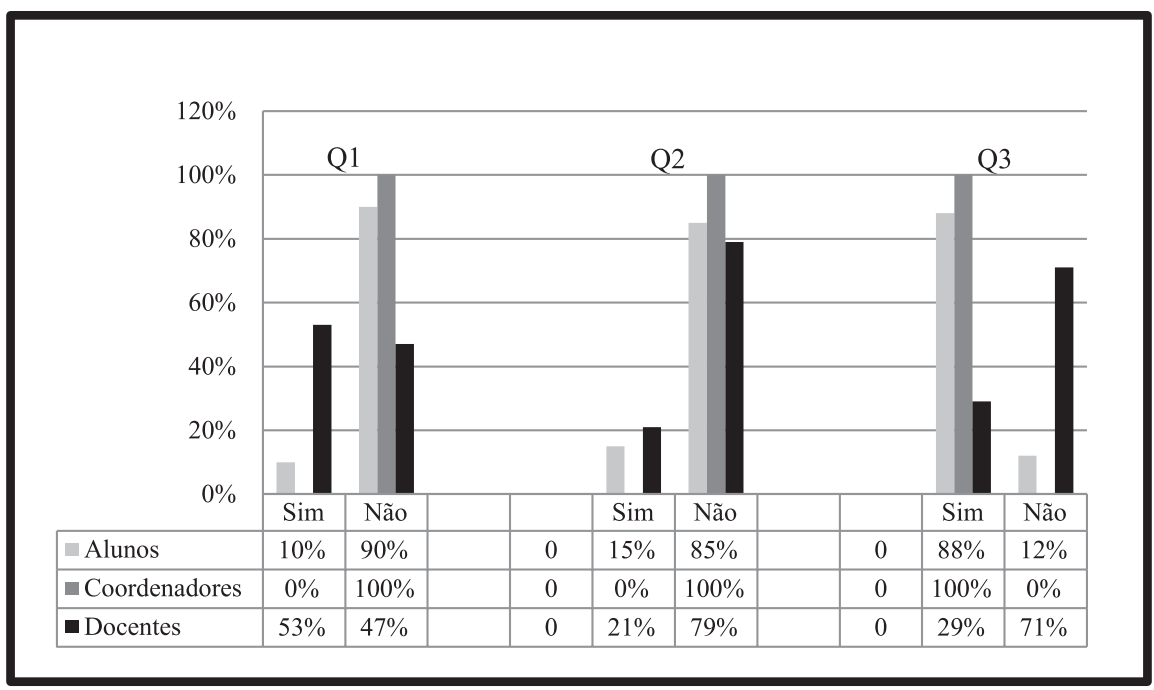

Fonte: Dados sistematizados pelo autor.

Gráfico 1 - Respostas de alunos, coordenadores e docentes às perguntas Q1, Q2 e Q3

Em relação à Q1, a maioria dos alunos (90\%) diz não haver problemas metodológicos na aplicação da avaliação docente. Portanto, para esses alunos os professores mantém uma postura pedagógica adequada, mesmo durante o período da aplicação da avaliação docente na escola. Entende-se, nesse contexto, como prática pedagógica docente adequada ações condizentes a um educador na relação professor-aluno, esclarecimento de dúvidas, manutenção da ordem e da disciplina em sala de aula, modelo e nível de prova bimestral aplicada aos alunos, utilização de material didático compatível à série trabalhada, assiduidade e pontualidade.

Contudo, nas entrevistas e com apoio da técnica da observação, identificaramse, em conversas pelos corredores da escola, com parte desses noventa alunos, afirmações contrárias, inclusive com identificação nominal dos docentes que adotam posturas pedagógicas incongruentes às ações convencionadas do educador.

Identifica-se outro impasse, este no corpo de coordenadores da instituição, ao não admitirem, nos questionários, existir problemas metodológicos na avaliação docente. Porém, novamente com base na observação sistemática e na entrevista, percebeu-se, no discurso da própria coordenação, que existem problemas no momento da aplicação da avaliação docente aos alunos.

Em decorrência da observação sistemática, as distorções são logo perceptíveis pela pressa da equipe de coordenadores no momento de aplicação da avaliação docente às turmas. É como se eles quisessem livrar-se o mais rápido possível dessa tarefa. Assim, não ocorre o esclarecimento adequado do significado de cada 
pergunta contida no questionário da avaliação docente. Logo, durante a aplicação do instrumento, a equipe de coordenadores também não promove uma adequada explicação para os alunos-avaliadores sobre a importância desse tipo de avaliação para o processo de ensino-aprendizagem. Algumas vezes, por meio da observação sistemática, foi possível constatar funcionários da escola não qualificados para aplicar a avaliação docente substituindo, em algumas turmas, os coordenadores/ aplicadores.

Ao mesmo tempo, 11 dos 24 docentes afirmam, também, não haver problemas metodológicos na avaliação docente. Contudo, constatou-se, na entrevista, que a maioria (47\%) alega ter receio de alguma retaliação da direção da escola se esta souber de suas críticas à metodologia da avaliação docente.

$\mathrm{Na}$ Q2, apenas $15 \%$ dos alunos informaram que a avaliação é utilizada como mecanismo de vindita. A maior parte, embora tenha respondido no questionário que a avaliação docente não apresenta esse caráter, evidenciou postura diferenciada na entrevista.

A totalidade dos coordenadores afirma que os alunos não utilizam a avaliação docente como forma de promover retaliações a ações de determinado professor.

No entanto, considerando comentários dos coordenadores nas entrevistas, esse tipo de avaliação parece ser, sim, utilizada para retaliar determinados docentes que, por um motivo ou outro, não agradaram ao aluno, ao seu grupo e/ou à sua turma. Embora $79 \%$ dos docentes tenham afirmado não existir o caráter de vindita por parte dos alunos, admitiram, quando entrevistados, temer as atitudes dos alunos.

No contexto da Q3, o principal ponto a ser ressaltado é a opinião da maioria dos docentes (71\%), que são categóricos quanto ao descrédito nos resultados e efeitos da avaliação docente. Em contrapartida, 78\% dos alunos e a totalidade dos coordenadores afirmam que os resultados da avaliação docente têm credibilidade perante a comunidade escolar. Com base nos resultados, constatam-se alterações na prática pedagógica por parte de professores na tentativa de defender-se das ações retaliadoras de alunos e, posteriormente, da própria direção da escola.

Outras respostas às perguntas contidas no questionário aplicado aos alunos, coordenadores e docentes foram comparadas com as respostas obtidas na entrevista, complementadas pela observação sistemática, para concluir se a avaliação docente altera a prática pedagógica do corpo docente. As perguntas comparadas foram as seguintes:

Q4 - O professor, no bimestre de aplicação da avaliação docente, conclui em tempo hábil e de forma compatível à série do aluno o seu conteúdo programático direcionado às provas bimestrais? 
Q5 - O nível das questões inseridas nas provas bimestrais, que coincidem com o período de aplicação da avaliação docente, é compatível ao nível da série do aluno?

Q6 - O docente mostra-se mais disposto a contribuir com os alunos, esclarecendo as dúvidas pertinentes ao conteúdo da matéria ministrada, no período em que a avaliação docente é aplicada?

Q7 - O docente mantém a ordem e a disciplina na sala de aula no período próximo à avaliação docente?

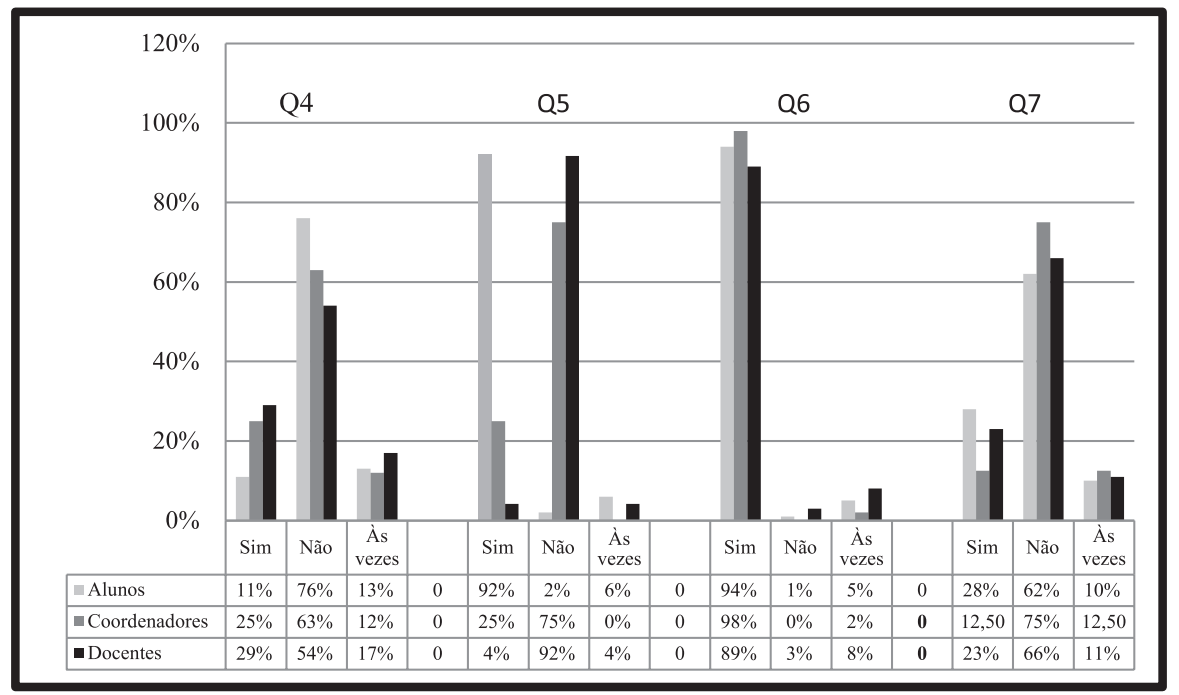

Fonte: Dados sistematizados pelo autor.

Gráfico 2 - Resposta de alunos, coordenadores e docentes às perguntas Q4, Q5, Q6 e Q7

Considerando as respostas dos alunos à Q4, constata-se que a maioria dos professores (76\%), no bimestre de aplicação da avaliação docente, não conclui em tempo hábil e de forma compatível à série do aluno seu conteúdo programático direcionado às provas bimestrais. Esses números são referendados pela maioria, na entrevista, aferindo que a maior parte do corpo docente trabalha um conteúdo mais reduzido e fácil em relação ao nível da série do aluno.

Além disso, apenas $11 \%$ dos alunos afirmam que o corpo docente cumpre a programação de forma adequada. Os coordenadores confirmam a opinião dos alunos, pois 63\% deles também asseveram que os professores não concluem o conteúdo programático adequadamente e no prazo estabelecido. É interessante notar que $54 \%$ do total de 24 docentes corroboram a opinião dos alunos e coordenadores em suas respostas ao questionário. Por fim, no critério da Q4, 71\% do conjunto que respondeu ao questionário identificaram alteração na prática pedagógica docente. 
Em relação à Q5, verifica-se que o nível das questões inseridas nas provas bimestrais, que coincidem com o período de aplicação da avaliação docente, não é compatível ao nível da série do aluno. A maioria dos coordenadores e docentes, respectivamente, $75 \%$ e $92 \%$ daqueles que responderam ao questionário, afirma que as questões aplicadas nas provas bimestrais são de nível inferior à série do aluno. Contudo, os alunos - que, obviamente, não têm formação pedagógica para mensurar o nível de questão aplicada em prova - responderam em sua maioria o contrário, ou seja, 92\% assinalaram que o nível das questões é compatível à sua série. Entende-se que, para a maioria dos discentes, quanto mais fácil for a prova, melhor.

$\mathrm{Na}$ análise da Q6, somente uma minoria de alunos (1\%) e de professores (3\%) afirma que o corpo professoral não se interessa em esclarecer as dúvidas pertinentes ao conteúdo da matéria ministrada no período em que a avaliação docente é aplicada. Assim, considera-se que a maioria dos docentes expressa maior atenção aos alunos como forma de ser melhor avaliado durante o processo, a fim de não receber restrições por parte do proprietário/gestor da escola.

Em relação à Q7, a maioria dos docentes e coordenadores, respectivamente $66 \%$ e $75 \%$, afirma que o corpo docente apresenta posição passiva em relação ao comportamento disciplinar do aluno. Novamente, quando comparadas as respostas dos questionários com as entrevistas, a maior parte dos docentes admite adotar essa postura com receio de punição por parte dos alunos e de consequentes reações do proprietário/gestor da escola.

O Gráfico 3 apresenta as respostas de docentes e coordenadores para a pergunta abaixo:

Q8 - O proprietário/gestor da escola utiliza a avaliação docente como instrumento antidemocrático e através dos resultados adota medidas restritivas aos docentes como perda de carga horária e demissão funcional? 


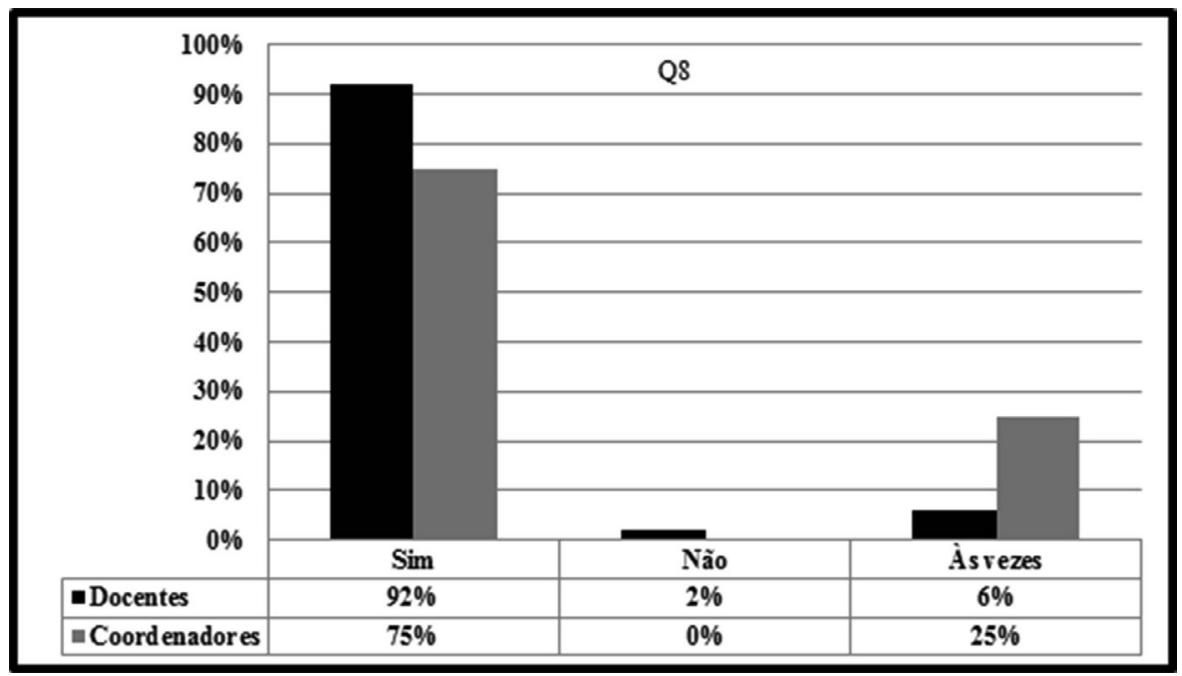

Fonte: Dados sistematizados pelo autor

Gráfico 3 - Resposta de docentes e coordenadores à pergunta Q8

Os percentuais expressos no Gráfico 3 evidenciam que o corpo docente e os coordenadores do centro de estudos pesquisado concordam que a avaliação docente é utilizada, pelo proprietário/gestor escolar, como instrumento antidemocrático, respaldando suas decisões nada convenientes para os professores. Afinal, basta que a maioria dos discentes os avalie abaixo do padrão esperado para que sejam penalizados com perda da carga horária daquela referida turma e até mesmo com a demissão funcional, se o baixo desempenho for apontado por um maior número de turmas.

Contudo, para a direção do centro de estudos pesquisado, a avaliação docente corresponde ao processo norteador de suas decisões em qualquer abrangência e instância, sejam elas pedagógicas, de infraestrutura ou administrativas. Ainda que admitam existir falhas em sua metodologia, os gestores entendem que estas não chegam a comprometer o resultado final do processo.

\section{Conclusão}

O processo avaliativo docente deve proporcionar informações gerais e consistentes sobre a qualidade de um programa educativo ou de um centro educacional em toda a sua amplitude. A investigação procurou identificar se a aplicação da avaliação docente, enquanto instrumento de gestão antidemocrática, altera a prática 
pedagógica do corpo de professores do centro de estudos pesquisado, influenciando no processo de ensino-aprendizagem.

Os resultados da avaliação docente oferecem condições para se refletir sobre a qualidade do ensino prestada pela instituição. Da maneira como sua metodologia é tratada, torna-se incontestável a ocorrência de alterações na prática pedagógica por parte de alguns docentes, promovendo, assim, a quebra de modelos paradigmáticos educacionais e acarretando prejuízos à evolução contínua, constante e de qualidade do processo ensino-aprendizagem prestado pelo centro de estudos pesquisado.

Considerando-se os resultados da pesquisa, constatou-se a ocorrência de equívocos metodológicos na aplicação da avaliação docente, pois os alunos a utilizam como forma de promover retaliações aos professores, perante os quais os resultados da avaliação não têm credibilidade. Nesse contexto, recomenda-se a elaboração de plano metodológico da avaliação docente, contendo, de forma explícita, os objetivos da avaliação, o que se pretende avaliar, quais as partes da escola a serem avaliadas, quem participará da metodologia da avaliação e quais serão suas funções, quais obstáculos à avaliação pode encontrar durante a sua aplicação, enumeração de modo antecipado e de supostos problemas a serem detectados, quais as medidas corretivas a serem tomadas e quais utilidades os resultados da avaliação poderão ter.

Ainda, os dados obtidos na pesquisa evidenciaram que: o docente não conclui em tempo hábil e de forma compatível à série correspondente o conteúdo programático direcionado às provas bimestrais, quando essas provas ocorrem no mesmo período da aplicação da avaliação docente; que o nível das questões inseridas nas provas bimestrais não é compatível ao da série do aluno; que o docente mostra-se mais disposto a contribuir com os alunos, esclarecendo as dúvidas pertinentes ao conteúdo da matéria ministrada, no período em que a avaliação docente é aplicada; e que o docente não se preocupa com a disciplina em classe nesse período. Assim, recomenda-se um planejamento do processo avaliativo, para que não haja equívocos metodológicos prejudiciais aos sujeitos da comunidade escolar e, sobretudo, para que a avaliação não redunde em descrédito total por parte dos sujeitos envolvidos, principalmente do corpo docente, comprometendo, ao final, o processo de aprendizagem do alunado.

Concluiu-se, ainda, que o proprietário/gestor da escola utiliza a avaliação docente como instrumento antidemocrático e, com base nos resultados, adota medidas restritivas aos docentes, como perda de carga horária e demissão funcional. Nesse caso, recomenda-se que se instituam mecanismos para implantar cultura metodológica avaliativa a ser aplicada não só aos docentes, mas a todos os sujeitos que compõem a instituição. Para tanto, pode-se promover a formação de um comitê de trabalho com pelo menos um integrante de cada grupo de sujeitos envolvidos no 
processo de avaliação (direção, pais e/ou responsáveis financeiros, docentes, alunos, coordenação, secretaria, infraestrutura, serviços gerais e apoio, entre outros, se houver), a fim de se iniciar o planejamento metodológico da avaliação-ibope. Assim, será possível ter uma visão mais ampla do que se avaliar no contexto geral da instituição.

É fundamental, também, a criação de um parâmetro de qualidade para todos os itens da avaliação, que passará a ser entendido como padrão de excelência e distinção. É importante que os resultados sejam visíveis não somente por meio do informe final aos sujeitos da comunidade escolar avaliados, mas, principalmente, que esses resultados redundem em mudanças de atitudes de sua parte, para que seja possível absorver a cultura de avaliação como a busca constante da evolução do grau de qualidade da educação proporcionada pelo centro de estudos em toda a sua amplitude.

O resultado final da avaliação, em relação aos docentes, não deve prezar pelo aspecto meramente punitivo, sendo importante que a comunidade escolar aceite, sem restrições, as medidas administrativas tomadas pela direção da escola em busca da correção de equívocos metodológicos ou de problemas detectados mediante os dados quantitativos e qualitativos obtidos na avaliação.

A avaliação docente não pode ter caráter restritivo da prática pedagógica docente, mas deve constituir-se em momento de expectativa pelos sujeitos da instituição, para que, com seus resultados, busque-se a melhoria do processo de ensino-aprendizagem.

Assim, considera-se que os equívocos metodológicos aqui detectados poderão ser minimizados, gradativamente, até que a avaliação se torne componente da cultura da escola e seu momento de aplicação seja revestido de expectativa por todos os sujeitos da instituição, a fim de que, com a análise dos resultados, busque-se a melhoria planejada, organizada e coerente do processo de ensino-aprendizagem.

\section{Undemocratic teaching evaluation: influence on pedagogical practice}

\section{Abstract}

The research was developed in a center of private education, where pedagogical practice teaching is evaluated by students and their results give fulcrum for decision making of the owner / manager school. The article aims to identify the implementation of teacher evaluation, as a management tool undemocratic, alters the pedagogical practice teaching, influencing the teaching-learning process. The applied methodology is qualitative, grounded in phenomenological analysis, descriptive and bibliographic, with techniques of questionnaire, not standardized interview and systematic observation to note whether there is - or there isn't - the soundness in the answers. The results demons- 
trate that teaching evaluation provides, by the manager, faculty members and students, actions that are pedagogical restrictive, hierarchically retaliatory, controlling employers and punitive vinditas, coexisting, thus, by teachers, aversion to evaluation. The teaching evaluation cannot restrict the teaching pedagogical practice, but should constitute itself in a moment of expectation by the subjects of the institution in order to, with its results, try to improvement of teaching-learning process.

Keywords: Teacher evaluation. Undemocratic school management. Pedagogical practice.

\section{Referências}

AFONSO, A. J. Avaliação educacional: regulação e emancipação - para uma sociologia das políticas avaliativas contemporâneas. 3. ed. São Paulo: Cortez, 2005.

ANTUNES, C. Professores e professauros: reflexões sobre a aula e práticas pedagógicas diversas. 4. ed. Petrópolis, RJ: Vozes, 2010.

BLOOM, B. S.; HASTINGS, J. T.; MADAUS, G. F. Manual de avaliação formativa e somativa do aprendizado escolar. São Paulo: Pioneira, 1983.

CASTANHEIRA, A. M. P.; CERONI, M. R. Formação docente e a nova visão de avaliação educacional. Estudos em Avaliação Educacional, v. 19, n. 39, p. 119-121, jan./abr. 2008.

CHIAVENATO, I. Recursos humanos. Edição compacta. 6. ed. São Paulo: Atlas, 2000.

COSTA, J. de L. E agora? Quem me avalia é o aluno. Um estudo sobre a avaliação do desempenho docente. 2007. 119 f. Dissertação (Mestrado em Educação) - Faculdade de Educação, Universidade de Brasília, Brasília, 2007.

DEMO, P. Aposta no professor: cuidar de viver e de trabalhar com dignidade. Porto Alegre: Mediação, 2007.

Mediação, 2008.

Universidade, aprendizagem e avaliação: horizontes reconstrutivos. 3. ed. Porto Alegre:

DIAS SOBRINHO, J. D. Avaliação: políticas educacionais e reformas da educação superior. São Paulo: Cortez, 2004.

FREIRE, P. A importância do ato de ler. 26. ed. São Paulo: Cortez; Autores Associados, 1991.

Pedagogia da autonomia: saberes necessários à prática educativa. São Paulo: Paz e Terra, 1996.

FREITAS, L. C. Ciclos, seriação e avaliação: confronto de lógicas. São Paulo: Moderna, 2003. (Coleção Cotidiano Escolar).

HAYDT, R. C. C. Avaliação do processo ensino-aprendizagem. São Paulo: Ática, 1992.

LEITE, S. A. da S.; KAGER, S. Efeitos aversivos das práticas de avaliação da aprendizagem escolar. Ensaio: Avaliação e Políticas Públicas em Educação, v. 17, n. 62, p. 109-134, 2009.

LUCKESI, C. C. Avaliação educacional escolar: para além do autoritarismo. Tecnologia Educacional, Rio de Janeiro, v. 7, n. 61, p. 6-15, 1984.

- Avaliação da aprendizagem na escola: reelaborando conceitos e recriando a prática. 2. ed. Salvador: Malabares, 2005. 
MARTINS, G. de A. Avaliação de desempenho do docente. In: DOMINGUES, M. J.; SILVEIRA, A. (Org.). Gestão de ensino superior: temas contemporâneos. Blumenau, SC: Ed. da Furb, 2008. v. 1 , p. $51-62$.

MIZUKAMI, M. da G. N. Ensino: as abordagens do processo. São Paulo: EPU, 1986.

PERRENOUD, P. Avaliação: da excelência à regulação das aprendizagens - entre duas lógicas. Porto Alegre: Artmed, 1999.

RAMOS, M. G.; MORAES, R. Avaliação do desempenho de professores numa perspectiva qualitativa: contribuições para o desenvolvimento profissional de professores universitários. Revista Ibero-Americana de Educação, Madrid, n. 22, p. 01-18, 2000.

ROMÃO, J. E. Avaliação dialógica: desafios e perspectivas. 7. ed. São Paulo: Cortez; Instituto Paulo Freire, 2008.

SANTO, E. do E.; SANTOS, F. M. G. Avaliação de desempenho docente: um estudo de caso numa instituição de ensino superior privado em Salvador - Bahia, Brasil. In: COLOQUIO INTERNACIONAL SOBRE GESTIÓN UNIVERSITÁRIA EN AMÉRICA DEL SUR, 10, 2010, Mar Del Plata. Anais... Mar Del Plata, 2010. p. 1-15.

SILVA, E. L. da; MENEZES, E. M. Metodologia da pesquisa e elaboração de dissertação. 4. ed. rev. atual. Florianópolis: Laboratório de Ensino a Distância da UFSC, 2005.

SOUZA, A. de M. (Org.). Dimensões da avaliação educacional. Petrópolis, RJ: Vozes, 2005. 